\title{
Pelatihan Akuntansi dan Pelatihan Penggunaan Bahan Pengawet kepada Pengusaha Home Industri Roti Kacang
}

\section{Accounting Training and Training on The Use of Preserved Materials}

\author{
Ilham Ramadhan Nasution1) \& Sartini 2)
}

1)Program Studi Akuntansi Fakultas Ekonomi dan Bisnis Universitas Medan Area

2) Program studi Biologi Fakultas Saint dan Teknologi Universitas Medan Area

Diterima: 25 Januari 2020; Disetujui: 03 Maret 2020; Dipublish: 23 Maret 2020 *Coresponding Email: Ilham.nst@hotmail.com/Sartini@staff.uma.ac.id

\begin{abstract}
Abstrak
Kemajuan suatu usaha tergantung pada mau atau tidaknya mengadopsi suatu teknologi. Jika tidak mengikuti perkembangan teknologi maka akan tertinggal dan jika mengikutinya maka akan maju bersaing. Namun, adakalanya keinginan untuk hijrah mengikuti perkembangan jaman dari tradisional menjadi modern tidak disertai dukungan dari tenaga ahli sehingga dalam prakteknya pelaku pengusaha mencoba-coba sendiri tanpa perhitungan yang jelas, alhasil konsumen menjadi kelinci percobaannya dari ketidaktahuannya. Seperti pada pengabdian kali ini, pengusaha roti kacang selama 10 tahun berdiri tidak mengalami kemajuan dalam usahanya, berbagai masalah turut mengambil andil dalam mempengaruhi keuntungan penjualan seperti masalah harga bahan baku untuk pembuatan roti kacang yang tidak stabil, kapasitas kemampuan dalam memproduksi roti kacang setiap harinya terbatas, masa kadaluarsa yang terlalu cepat, kemasan yang tidak menarik dan tidak memenuhi syarat untuk memperoleh bantuan modal dari bank karena tidak mempunyai buku laporan keuangan perusahaan. Dari masalah di atas penulis ingin memberikan solusi dengan melakukan kegiatan pengabdian kepada masyarakat. Solusi yang ditawarkan adalah memberikan pemahaman tentang bahan pengawet serta pelatihan penggunaan bahan pengawet untuk memperpanjang masa kadaluarsa, melakukan pelatihan dalam penyusunan laporan keuangan dan memberikan design kemasan produk yang menarik. Diharapkan dengan melakukan kegiatan pengabdian kepada masyarakat ini usaha mitra dapat berkembang.
\end{abstract}

Kata Kunci: Pelatihan, Pengawet, Roti kacang, Akuntansi,

\section{Abstract}

The progress of a business depends on whether or not to adopt a technology. If you don't follow technological developments, you will be left behind and if you follow them, you will compete. However, sometimes the desire to emigrate to follow the development of the times from traditional to modern is not accompanied by support from experts so that in practice entrepreneurs try themselves without clear calculations, as a result consumers become guinea pigs from their ignorance. As in the dedication this time, the business of nut bread for 10 years has not made progress in its business, various problems also take part in influencing sales profits such as the issue of raw material prices for making unstable bean bread, capacity capacity in producing peanut bread every day is limited, the expiration period is too fast, the packaging is not attractive and does not meet the requirements to get capital assistance from banks because they do not have a book of financial statements. From the above problems the writer wants to provide a solution by doing community service activities. The solution offered is to provide an understanding of preservatives and training in the use of preservatives to extend the expiration period, conduct training in the preparation of financial statements and provide attractive product packaging designs. It is hoped that by carrying out community service activities this partner's business can develop. Keywords: Tranning, Preservatives, Peanut Bread, Accounting

How to Cite: Nasution, I.R. \& Sartini. (2020). Pelatihan Akuntansi dan Pelatihan Penggunaan Bahan Pengawet kepada Pengusaha Home Industri Roti Kacang. Journal of Education, Humaniora and Social Sciences (JEHSS). 2(3): 573-577. 


\section{PENDAHULUAN}

Pemerintah pusat maupun daerah senantiasa perlu menggali berbagai potensi yang tersedia pada masing-masing daerah. Salah satu upaya untuk meningkatkan potensi ekonomi di daerah adalah menghidupkan sektor industri termasuk industri rumah tangga "Industri telah diakui sebagai sektor penunjang utama pembangunan regional. Kegiatan ini memang beralasan, mengingat banyaknya daerah yang ditunjang oleh industri, ternyata memperlihatkan hasil yang cukup menggembirakan “, Kartanto, (2012).

Roti merupakan produk pangan yang paling populer. Walaupun di Indonesia roti bukan sebagai makanan pokok, namun roti karena kepraktisannya dimakan pada saat sarapan pagi hari terutama oleh masyarakat perkotaan. Jenis roti pun bervariasi ada roti tawar, roti manis dan lain-lain. Roti manis diisi bagian dalamnya dengan strawberi, srikaya kelapa, coklat, daging, krim dan lain sebagainya (Inuraida, 2014).

Untuk mempertahankan rasa dan ketahanan roti agar tidak berjamur pelaku usaha menambahkan zat pengawet, jumlah dosis yang diberikan akan mempengaruhi rasa dan daya tahan roti terhadap jamur. Semakin banyak digunakan dapat berakibat masalah bagi pencernaan. Bahan pengawet makanan tidak berbahaya untuk kesehatan tubuh manusia jika pemakaiannya tidak berlebihan. Namun, karena biasanya setiap zat pengawet makanan yang tidak berbahaya memiliki efek samping tersendiri didalam kandungannya https://www.kucobalagi.com/bahan-pengawet-makanan-yang-tidakberbahaya-untuk-kesehatan.html

Membangun usaha pabrik roti dengan skala rumahan bisa menjadi pilihan bagi yang sedang mencari bisnis yang menguntungkan. Usaha rumahan seperti ini termasuk kedalam kategori home industri yang tidak membutuhkan modal terlampau besar dan dapat dijalankan dengan lokasi space yang terbatas hanya dengan memanfaatkan dapur atau garasi rumah usaha ini sudah bisa berjalan mengingat perlatan yang berupa mesin tidak begitu besar.

Pada kesempatan ini penulis berencana untuk melakukan pengabdian kepada masyarakat dengan judul "Pelatihan Akuntansi dan Pelatihan penggunaan bahan pengawet bagi pengusaha home industri roti kacang". Dalam melaksanakan kegiatan ini tahap awal adalah dilakukannya analisis situasi untuk mendapatkan informasi tentang usaha rumahan produksi roti kacang dengan mengadakan survey ke lapangan. Lokasi 
yang dipilih adalah wilayah Kota Medan tepatnya di jalan Letda Sujono di Kelurahan Bandar Selamat Kecamatan Medan Tembung. Dari hasil diskusi dengan Bapak Ismail sebagai pelaku usaha home industri roti kacang tradisional dapat kami simpulkan bahwa: Bapak Ismail adalah pengusaha industri rumahan roti kacang yang telah berjalan selama 10 Tahun dengan mempunyai 5 Anggota. Jumlah roti setiap harinya diproduksi sesuai dengan pesanan karena roti yang diproduksi tidak dapat bertahan lama atau sekitar 5 hari. Wilayah pemasarannya adalah Medan, Binjai dan Deliserdang. Roti dijual oleh pengumpul atau agen. Jika roti tidak habis terjual maka yang menanggung kerugian tersebut adalah Bapak Ismail.Kenaikan harga kedelai juga mempengaruhi keuntungan yang diperoleh karena harga roti kacang tidak dinaikan pada saat harga kedelai naik. Selain itu produksi kedelai dalam sehari sangat terbatas karena oven pemasakan yang berkapasitas kecil hanya 1 (satu) unit. Bapak Ismail juga sudah mencoba untuk meminjam tambahan modal namun karena salah satu syarat seperti laporan keuangan perusahaan tidak ada maka pihak bank belum dapat mengucurkan dananya untuk bekerjasama mengembangkan usaha home industri ini.

\section{METODE PELAKSANAAN}

Untuk mengatasi masalah-masalah diatas Tim dan Mitra telah berdiskusi, metode pelaksanaan pengabdian kepada masyarakat yang akan dilaksanakan adalah sebagai berikut: 1) Memberikan pelatihan tentang penggunaan bahan pengawet sesuai dengan dosis yang diijinkan oleh pemerintah dan aman untuk dikonsumsi; 2) Memberikan bantuan peralatan oven untuk meningkatkan kapasitas produksi; 3) Mendesign kemasan agar menarik; 4) Memberikan pelatihan akuntansi tentang laporan keuangan perusahaan.

Metode pelaksanaan yang akan dilakukan tim pengabdian masyarakat diatas telah dipaparkan kepada mitra dan mitra menyambut positif atas rencana tersebut diatas dengan harapan dengan usaha roti kacang dapat berkembang.

\section{HASIL DAN PEMBAHASAN}

Dari hasil kegiatan dapat dilaporkan bahwa: 1) Roti kacang yang menggunakan pengawet dapat bertahan sampai 30 hari dibandingkan dengan yang tidak menggunakan pengawet; 2) Kemasan roti kacang yang sebelumnya hanya dibungkus dengan kertas dan 
kemasan plastik, kini dibungkus dengan kotak yang lebih menarik dan elegan; 3) Laporan debet dan kredit kini dibukukan dalam bentuk laporan keuangan.

Pelatihan akuntansi atau penyusunan laporan keuangan perusahaan dilaksanakan dengan lancar, Tim memberi contoh sebuah laporan debet kredit pada suatu UMKM dan mitra mencoba untuk memasukan semua uraian dalam segala transaksi yang dilakukan dalam satu minggu. Tim mengoreksi laporan yang dibuat mitra kesesuaian debet dan kredit.

Roti yang tidak menggunakan pengawet (Gambar 1) kelihatan pada kulitnya tumbuh jamur sedangkan yang menggunakan pengawet pada gambar 2 kelihatan bersih tanpa adanya jamur yang tumbuh pada permukaan kulit roti kacang pada umur roti 2 minggu. Dosis pengawet yang tepat (sesuai) tidak akan mempengaruh rasa dari roti kacang, sebaliknya jika pengawet yang diberikan terlalu banyak akan mempengaruhi rasa roti kacang itu sendiri.

Tim memberikan contoh kemasan roti kacang dalam bentuk kotak, dimana kemasan yang elegan dapat menambah nilai jual roti kacang. Namun Designnya kembali diserahkan kepada mitra sesuai dengan seleranya.

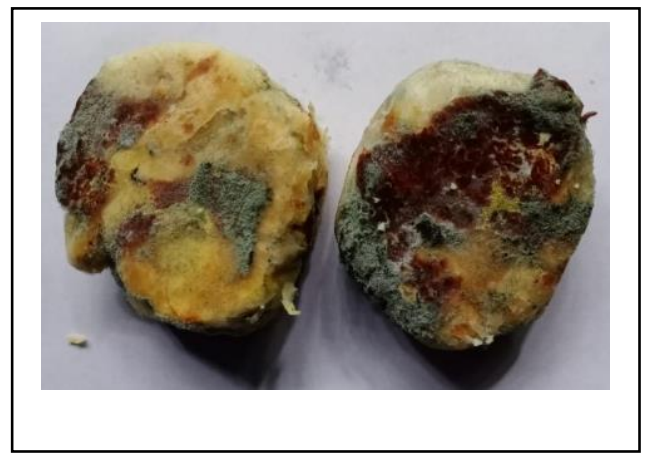

Gbr.1. Roti Kacang umur 2 Minggu (Tidak menggunakan Pengawet)

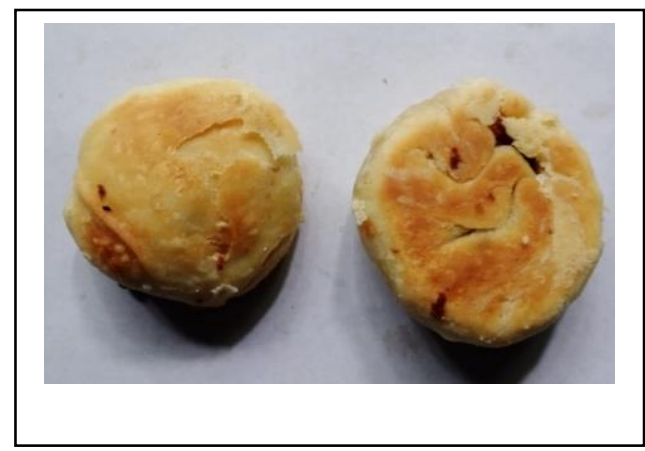

Gbr. 2. Roti kacang umur 2 Minggu (Menggunakan pengawet)

\section{SIMPULAN}

Kegiatan pengabdian kepada masyarakat berjalan sesuai dengan rencana; Penambahan zat pengawet telah menambah waktu penghambatan pertumbuhan bakteri jamur pada kulit roti kacang; Dosis pengawet yang tepat tidak akan mempengaruhi rasa dari roti kacang; Mitra dapat menerima pelatihan dalam pembuatan laporan keuangan; Mitra menerima saran dari kami untuk membungkus roti kacang dalam bentuk kemasan kotak. 


\section{UCAPAN TERIMA KASIH}

Tim Pengabdian Kepada Masyarakat ingin berterima kasih kepada Pengurus Yayasan Pendidikan Haji Agus Salim Universitas Medan Area dan Rektor Univeristas Medan Area yang telah memberikan dukungan penuh terhadap kegiatan ini dalam bentuk bimbingan dan materi sehingga kegiatan ini dapat berjalan sesuai yang direncanakan.

\section{DAFTAR PUSTAKA}

Mardi, K. (2012), Pembangunan Perindustrian Di Indonesia, Erlangga, Jakarta Bilson, B, (2013), Riset Pemasaran, (Falsafah, Teori dan aplikasi, Rineka Cipta, Jakarta Sukadji, (2010), Industri dalam Perkembangannya, Balai Pustaka, Jakarta. http://m.detik.com>food>info-kuliner Inuraida.staff.ipb.ac.id/kerusakan-dan-pengawetan-roti/

https://www.kucobalagi.com/bahan-pengawet-makanan-yang-tidak-berbahaya-untuk-kesehatan.html 